\title{
A New Anatomical Pathway of Spread of Pus/ Sepsis in Anal Fistulas Discovered on MRI and Its Clinical Implications
}

\author{
Pankaj Garg (D) \\ Baljit Kaur ${ }^{2}$ \\ Vipul D Yagnik (D) ${ }^{3}$ \\ Sushil Dawka (1D ${ }^{4}$ \\ 'Indus Super Specialty Hospital, Mohali, \\ India; ${ }^{2}$ Department of Radiology, SSRD \\ MRI Centre, Chandigarh, India; ${ }^{3}$ Nishtha \\ Surgical Hospital and Research Centre, \\ Patan, Gujarat, India; ${ }^{4}$ SSR Medical \\ College, Belle Rive, Mauritius
}

Background: In the anal sphincter complex, the intersphincteric space between the internal and external sphincters is the only conventionally recognized pathway for the spread of sepsis. However, there is another unrecognized space discovered on MRI, the "outersphincteric space", between the external anal sphincter and its lateral fascia along which pus can spread. An abscess in the intersphincteric space is easily drained into the rectum via the transanal route and is more likely to spread into the supralevator space. Conversely, an abscess in the outer-sphincteric space is difficult to drain transanally into the rectum and is more likely to become a transsphincteric abscess/fistula.

Methods: The MRIs of anal fistula patients operated over four years on intersphincteric abscesses were analyzed. The pattern of spread into the ischiorectal fossa and/or supralevator space and ease of drainage into the rectum through the transanal route were studied.

Results: Thirty-six patients were operated on to drain their intersphincteric abscesses through the anal canal. Two distinct patterns were noted. Twenty patients had abscesses in the intersphincteric space, which were easily drained into the rectum. Of them, 6/20 had supralevator extension, while only $1 / 20$ had spread to the ischiorectal fossa. In 16/36 patients, the abscess was in the outer-sphincteric space and could not be drained into the rectum. In 9/16 of these patients, pus spread into the ischiorectal fossa but supralevator spread did not happen in any patient.

Conclusion: Apart from the intersphincteric space, there is perhaps another unrecognized anatomical space - the outer-sphincteric space - discovered on MRI, through which pus can spread in anal fistulas or abscesses.

Keywords: anal fistula, intersphincteric, MRI, supralevator, ischiorectal fossa, outersphincteric

\section{Introduction}

Complex anal fistulas are difficult to manage. The success rate of most procedures is not satisfactory as the recurrence rates are very high in these fistulas. ${ }^{1}$ The accumulated knowledge of over a century falls short and a complete understanding of the pathophysiology of complex fistulas and the reasons for their high recurrence still elude us.

The role of sepsis in the intersphincteric space, the space between the internal and the external sphincters, has been known for several decades. Over the last few years, proper eradication of sepsis in the intersphincteric has been shown to improve success rates in complex fistulas. ${ }^{2}$ However, it seems that there is more to the intersphincteric space than what is obvious.
Correspondence: Pankaj Garg Indus Super Specialty Hospital, Mohali, |40607, India

Fax +91-9501011000

Email drgargpankaj@yahoo.com 
Conventionally, it is believed that in the sphincter complex (the internal and the external sphincters) there is only one potential space through which a fistula (pus/sepsis) extends. This is the space between the two sphincters (intersphincteric space) (Figure 1). On MRI, all the tracts within the sphincter complex, ie between the rectal lumen and the ischiorectal fossa, are assumed to be in the intersphincteric space ("radiological intersphincteric space") and are labelled as intersphincteric tracts/fistulas by radiologists. ${ }^{3}$

However, the recent availability of high-resolution MRI has enabled a detailed evaluation of complex anal fistulas and their relation to the sphincter complex. ${ }^{1,4}$ This was not possible few years back. The different patterns of extension of anal fistulas and their detailed evaluation on MRI suggest that there are in fact two spaces, rather than one, in the sphincter complex.

It seems that apart from the conventional intersphincteric space, there is another space lateral (outside) to this space, between the external sphincter and its external fascia (named as "outer-sphincteric space" in this manuscript) (Figure 1). Thus, the single "radiological intersphincteric space" perhaps contains two spaces, the conventional intersphincteric space and the newly hypothesized, outer-sphincteric space (Figure 1). There are distinct radiological features, which differentiate these two spaces. The new space perhaps plays a pivotal role in the pathophysiology of fistula extension and may have important implications in the management of the disease.

\section{Methods}

In a retrospective study, the MRI scans of patients operated on intersphincteric abscesses over a four-year period were studied. A team comprising of operating surgeons and the consulting radiologist assessed the MRI scans. Features analyzed included whether the external sphincter could be seen lateral to the intersphincteric abscess/tract or not, extension of the abscess/tract to the ischiorectal fossa or the supralevator space, and whether it was possible to drain or lay open the abscess into the rectum through the transanal route. The study was conducted in accordance with the Declaration of Helsinki and was approved by the Ethics Committee of the Indus International Hospital. Informed consent was taken from all the patients.

\section{Results}

The MRIs of 36 anal fistula patients operated over four years (September 2016 to August 2020) for intersphincteric abscesses/tracts were analyzed in detail (Table 1).

In 20/36 patients, the external sphincter muscle could be seen outside (lateral to) the abscess on MRI scan (Figure 2, upper panel, Figures 3-5). In these patients, the abscess could be easily and effectively drained into the anal canal. In $6 / 20$ patients, the fistula was extended to the supralevator space, while in only $1 / 20$ patients, the abscess had spread to the ischiorectal fossa (Table 1).

In the other 16/36 patients, the external sphincter could not be seen outside the abscess, and the abscess was

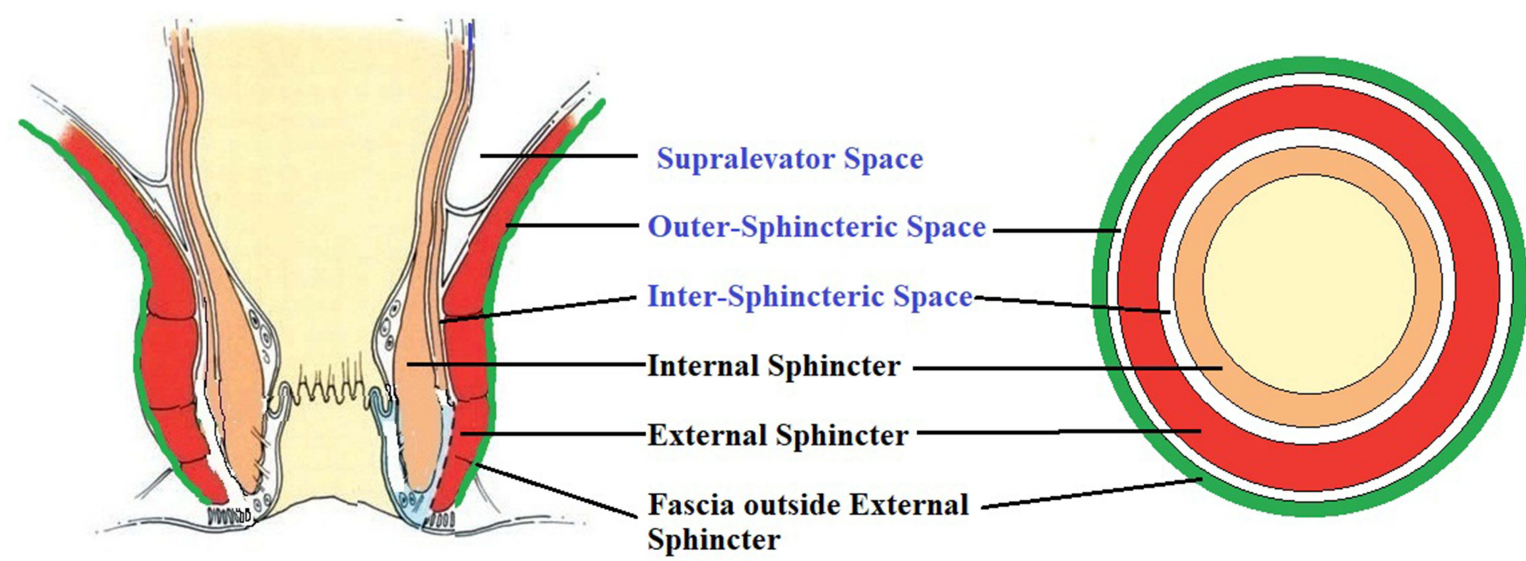

CORONAL SECTION

TRANSVERSE SECTION

Figure I Schematic diagram showing intersphincteric and outer-sphincteric spaces. 
Table I Distribution and Outcome of Perianal Abscesses $(n=36)$

\begin{tabular}{|l|l|l|}
\hline Abscesses & $\begin{array}{l}\text { Ontersphincteric } \\
\text { Space }\end{array}$ & 20 \\
\hline Number (Total N=36) & 16 \\
\hline $\begin{array}{l}\text { Abscesses which spread to the Supralevator space extending cephalad in the intersphincteric } \\
\text { space }\end{array}$ & 6 & 0 \\
\hline $\begin{array}{l}\text { Abscesses which breached the external covering fascia of the external anal sphincter and } \\
\text { spread to Ischiorectal fossa }\end{array}$ & I & 9 \\
\hline Abscesses which could be easily drained into the rectum through the transanal route & Yes & Outer (lateral to) the \\
\hline Position of external sphincter muscle in relation to abscess & $\begin{array}{l}\text { Inside (medial to) the } \\
\text { abscess }\end{array}$ \\
\hline
\end{tabular}

juxtaposed with the ischiorectal fossa fat (Figure 2, lower panel, Figures 6 and 7). These abscesses could not be drained into the anal canal. In $9 / 16$ of these patients, the pus had spread into the ischiorectal fossa. Supralevator spread did not occur in any of these patients.

Thus, the abscesses were Parks grade I when they were limited to intersphincteric space but became Parks grade III when the intersphincteric abscess spread to supralevator space. On the other hand, the abscesses in outer-sphincteric space were Parks grade II as these were technically transsphincteric fistulas (as they had breached the external anal sphincter, though they had not entered the ischiorectal fossa).

\section{Interpretation of the Above Results}

The above results highlight that there are two distinct spaces within the sphincter complex. These two spaces can be differentiated by the location of external anal sphincter on MRI.

-If the external sphincter could be seen outside the abscess/fistula tract, then the abscess was in the intersphincteric space (Figure 2, upper panel, Figures 3-5).

-If the external sphincter could not be seen outside the abscess/fistula tract and the abscess was juxtaposed with the ischiorectal fossa fat, then the abscess was in the 'outer-sphincteric' space (between the external sphincter

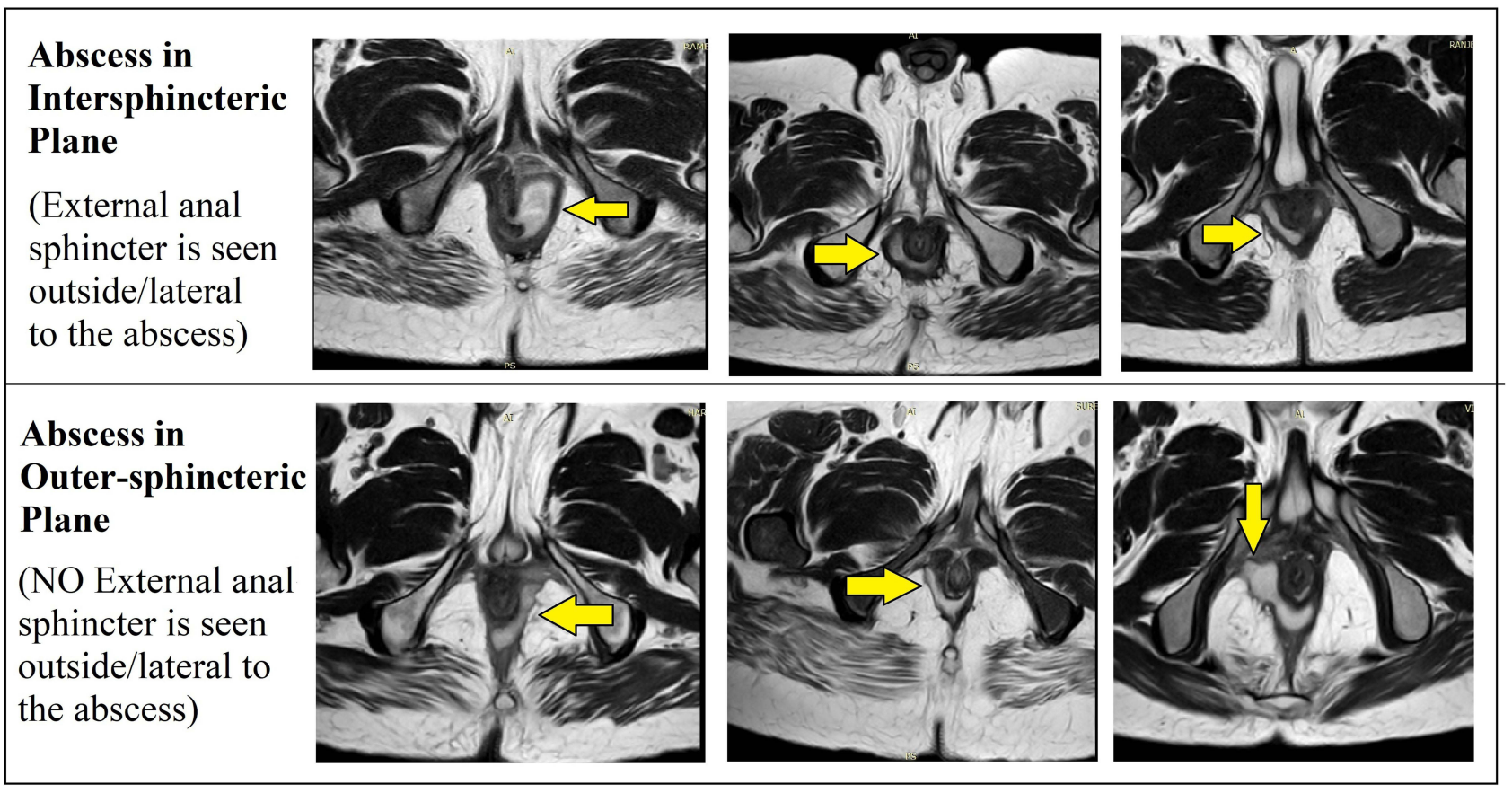

Figure 2 Upper panel: Abscess in the intersphincteric space (external sphincter muscle can be seen lateral to the abscess). Lower panel: Abscess in the outer-sphincteric space (external sphincter muscle cannot be seen lateral to the abscess and the abscess is juxtaposed to the fat in ischiorectal fossa). 


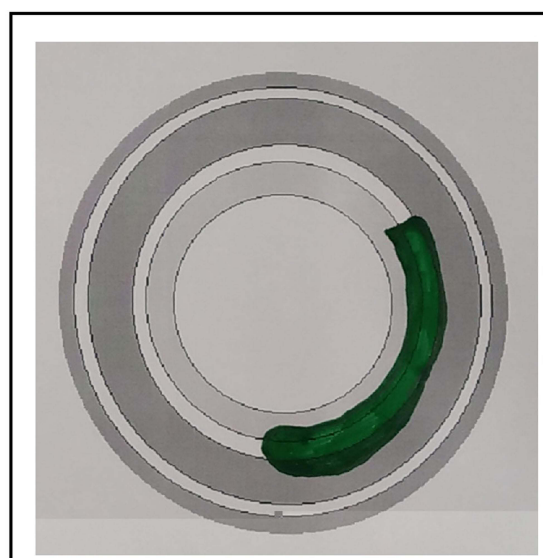

Schematic Diagram

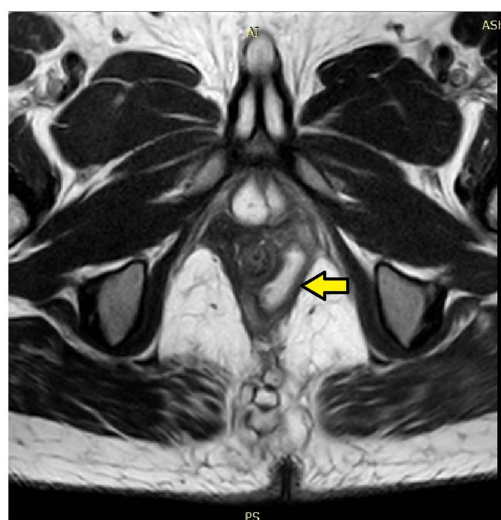

AXIAL - T2

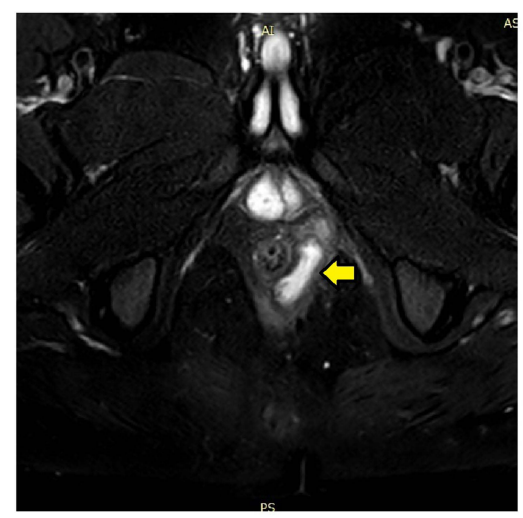

AXIAL- STIR

Figure 3 Abscess in left intersphincteric space from 3 to 6 o'clock. (external sphincter muscle can be seen lateral to the abscess). Abscess indicated by yellow arrows. Left panel: Schematic diagram. Middle panel: MRI axial section T-2 sequence. Right panel: MRI axial section STIR (Short T-I Inversion Recovery) sequence.

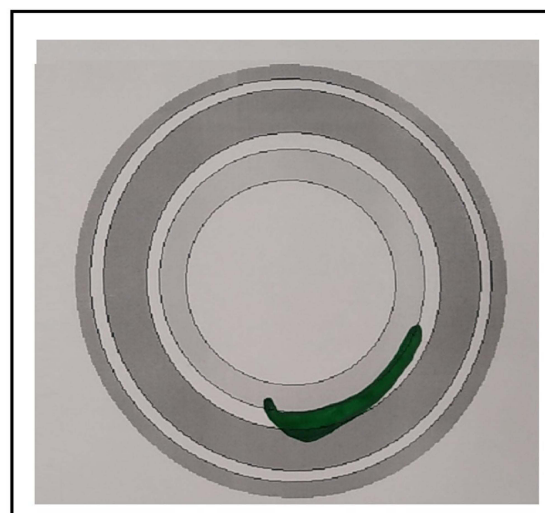

Schematic Diagram

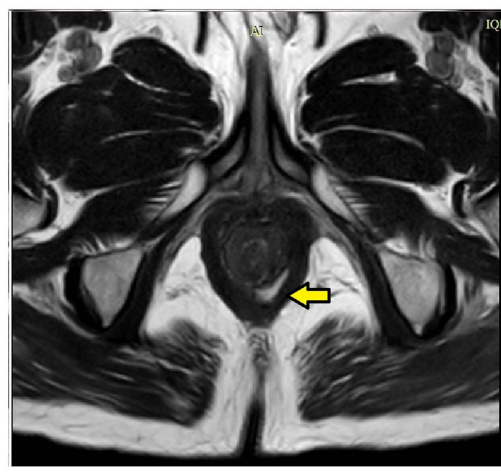

AXIAL - T2

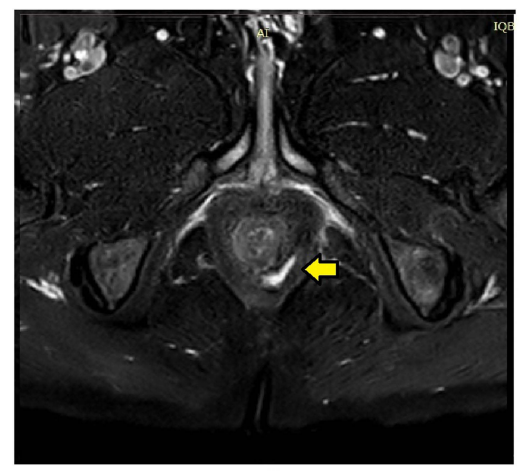

AXIAL- STIR

Figure 4 Abscess in left intersphincteric space from 4 to 6 o'clock. (external sphincter muscle can be seen lateral to the abscess). Abscess indicated by yellow arrows. Left panel: Schematic diagram. Middle panel: MRI axial section T-2 sequence. Right panel: MRI axial section STIR sequence.

and its external fascia) (Figure 2, lower panel, Figures 6 and 7).

\section{Discussion}

Apart from the conventional intersphincteric space, there is another previously undescribed pathway along which pus spreads leading to extension of the fistula. This new pathway lies between the external sphincter and its outer (lateral) fascia and has been named as the "outer-sphincteric space" to differentiate it from the "intersphincteric space" (Figure 1). Though radiologically, this hypothesized space lies within the sphincter muscle complex and is considered a part of the conventional intersphincteric space, it actually lies outside (lateral) to it (Figure 1).
The identification of this unrecognized space would perhaps help unravel key "confusions" associated with the pathophysiology of complex anal fistulas.

Both the diagnostic modalities, MRI and transanal ultrasound (TRUS), are quite effective in the evaluation of perianal abscesses and fistulas. However, MRI has some advantages over TRUS. The main advantage of MRI is that it has better resolution than MRI for deep-seated fistulas like supralevator or suprasphincteric fistulas. ${ }^{2-4}$ Secondly, unlike TRUS, MRI is not operator dependent. Unlike, TRUS, the MRI films can be independently assessed by any radiologist or surgeon. Therefore, MRI is considered the gold standard for the evaluation of perianal fistulas and abscesses. ${ }^{4}$ 


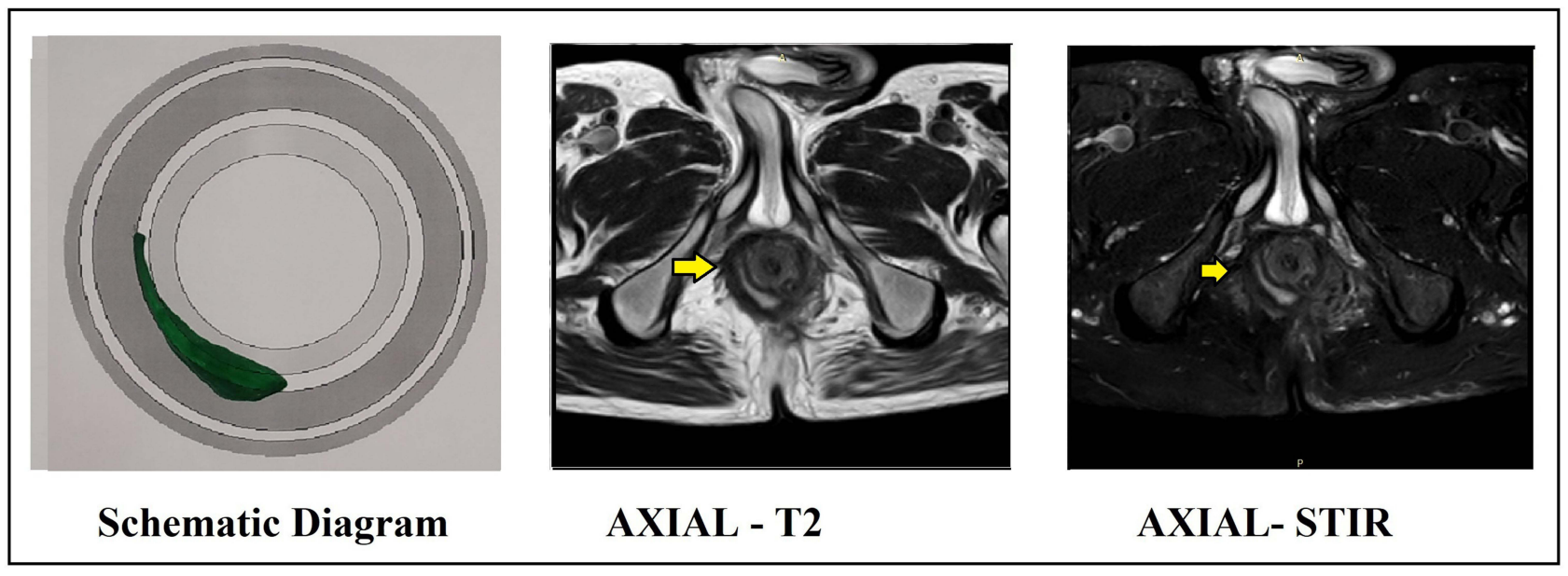

Figure 5 Abscess in right intersphincteric space from 9 to 6 o'clock. (external sphincter muscle can be seen lateral to the abscess). Abscess indicated by yellow arrows. Left panel: Schematic diagram. Middle panel: MRI axial section T-2 sequence. Right panel: MRI axial section STIR sequence.

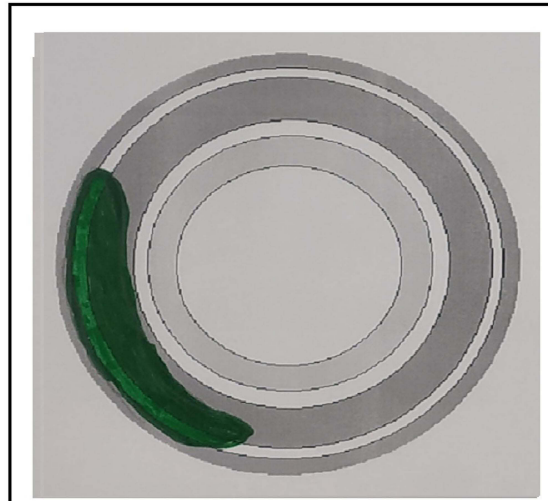

Schematic Diagram

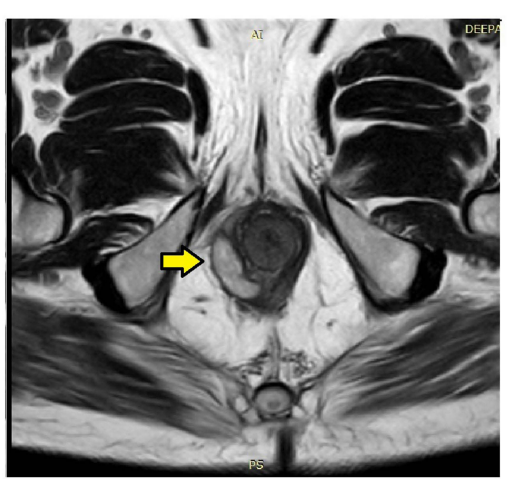

AXIAL - T2

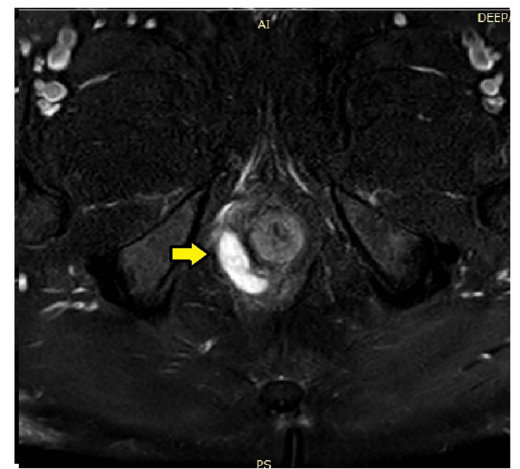

AXIAL- STIR

Figure 6 Abscess in right outer-sphincteric space from 9 to 7 o'clock. (external sphincter muscle cannot be seen lateral to the abscess and the abscess is juxtaposed to the fat in ischiorectal fossa). Abscess indicated by yellow arrows. Left panel: Schematic diagram. Middle panel: MRI axial section T-2 sequence. Right panel: MRI axial section STIR sequence.

Cryptoglandular fistulas are known to originate from anal glands that extend up to the intersphincteric space. ${ }^{5}$ However, the factors determining further extension of an abscess/fistula from the intersphincteric space to the transsphincteric space or the supralevator space are not clear. The identification of this pathway of pus spread helps determine which abscesses/fistulas tend to become transsphincteric fistulas and which are likely to spread into the supralevator space.

\section{Significance of the New ("Outer-}

\section{Sphincteric") Space in Pathophysiology of the Extension of Fistula}

Studying the path of spread of pus/fistula - The conventional intersphincteric space is in direct continuity with the supralevator space (Figure 8). Therefore, any abscess/ fistula in intersphincteric space is expected to spread to the supralevator space (Figure 8). On the other hand, the "outer-sphincteric space" is in juxtaposition with the ischiorectal fossa. Any abscess/fistula in the "outersphincteric space" would have a tendency to bulge or rupture into the ischiorectal fossa but is unlikely to spread to the supralevator space as there is an entire external sphincter between the "outer-sphincteric space" and the supralevator space (Figure 9).

\section{Implications of the Newly Described ("Outer-Sphincteric") Anatomical Space in Clinical Management}

Ease of drainage of abscess from inside the rectum (transanal route) - An abscess in the conventional intersphincteric 


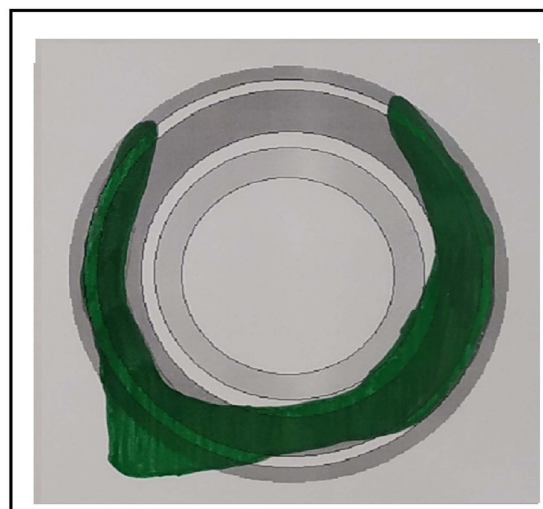

Schematic Diagram

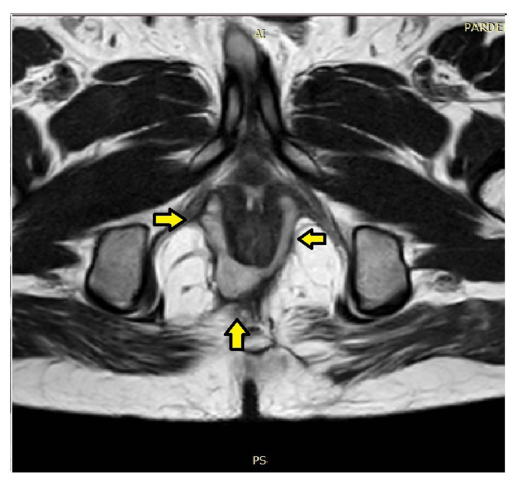

AXIAL - T2

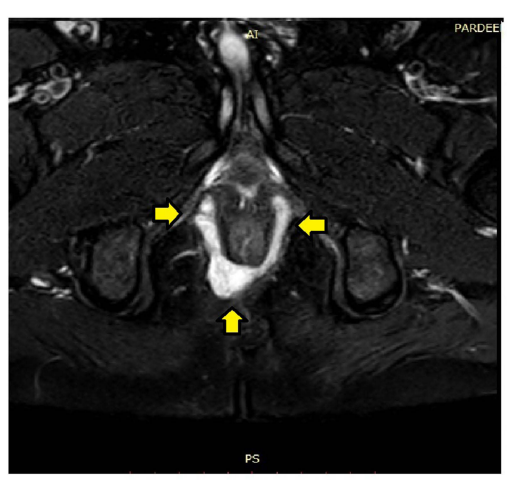

AXIAL- STIR

Figure 7 Horseshoe abscess with major component in outer-sphincteric space from 2 to 10 o'clock. (external sphincter muscle cannot be seen lateral to the abscess and the abscess is juxtaposed to the fat in ischiorectal fossa). Abscess indicated by yellow arrows. Left panel: schematic diagram. Middle panel: MRI axial section T-2 sequence. Right panel: MRI axial section STIR sequence.

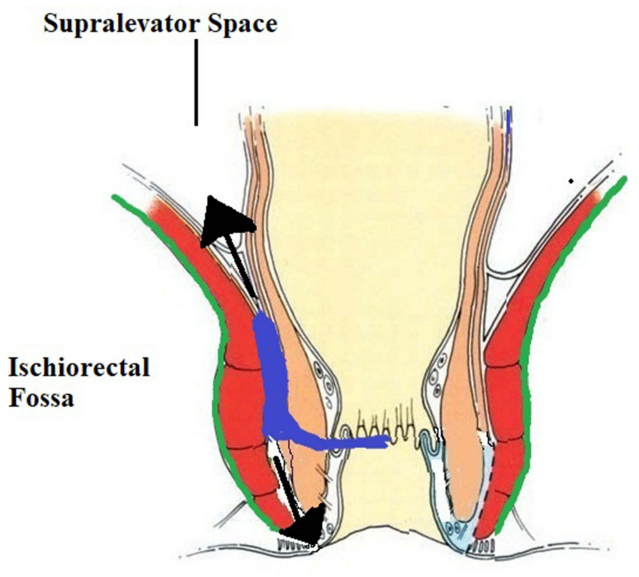

CORONAL SECTION

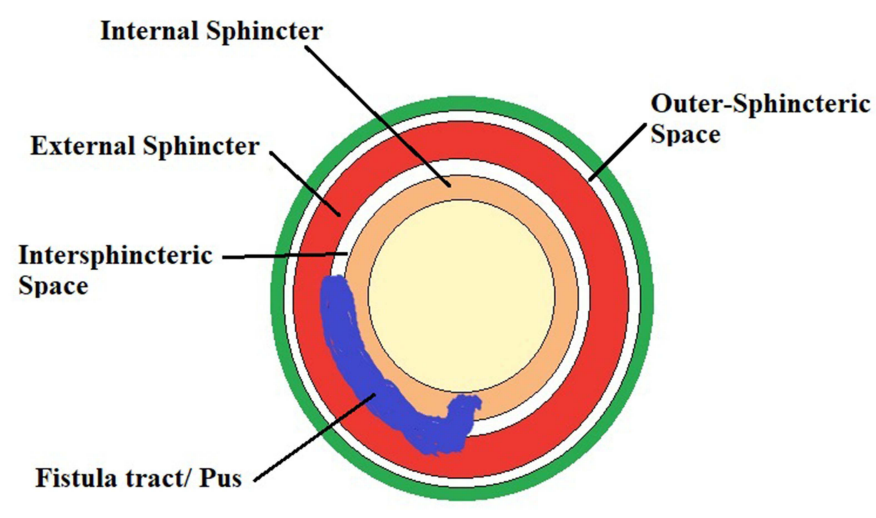

AXIAL SECTION

Figure 8 Schematic diagram highlighting abscess/fistula tract in the intersphincteric space and its propensity to spread to supralevator space.

space would be easier to drain from inside the rectum as there is only the internal sphincter separating it from the rectal lumen (Figure 8). On the other hand, an abscess in the "outersphincteric space" would be quite difficult to drain into the rectum because of the presence of both sphincters (internal and external sphincters) between the abscess and the rectal lumen (Figure 8). In the present study, the abscesses in the outer-sphincteric space were drained externally through the ischiorectal fossa, while the fistula tract in the intersphincteric space was managed by TROPIS (transanal opening of intersphincteric space) procedure. $^{6-8}$ TROPIS is a modification of LIFT (ligation of intersphincteric tract) in which the intersphincteric tract is opened up into the anal canal so that it heals by secondary intention. ${ }^{6-9}$
The ischioanal or ischiorectal abscess should not be drained into the anal canal as this will risk injuring the external anal sphincter (EAS). However, drainage of supralevator abscess into the anal canal is the preferred method as it would entail incising the internal anal sphincter (IAS) only and thus prevent injury to the external anal sphincter. ${ }^{10,11}$ The drainage of supralevator fistula through the ischioanal fossa would risk injury to EAS and would also risk formation of suprasphincteric fistula. ${ }^{10,11}$

On MRI, the sphincter muscles and their relation to the abscess are best assessed in the axial section T-2 sequence because both the abscess/fistula tract and the sphincter muscles are visualized in this sequence (Figures 2-7). On axial section $\mathrm{T}-1$ sequence, the abscess/fistula tract is not 


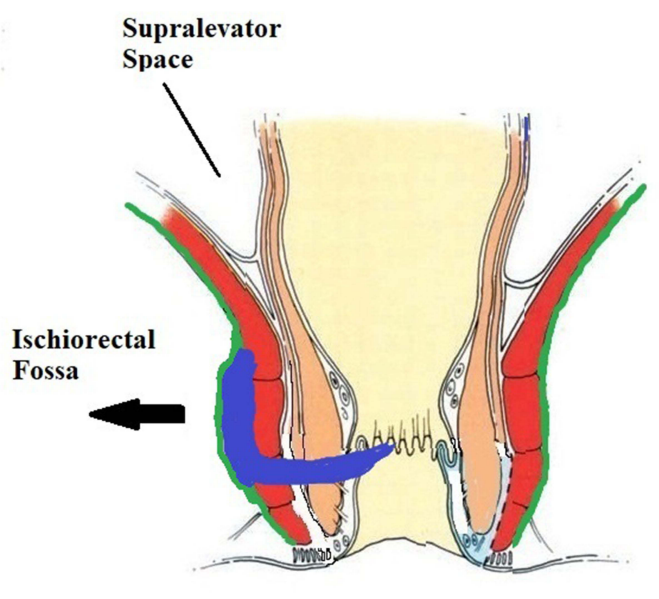

CORONAL SECTION

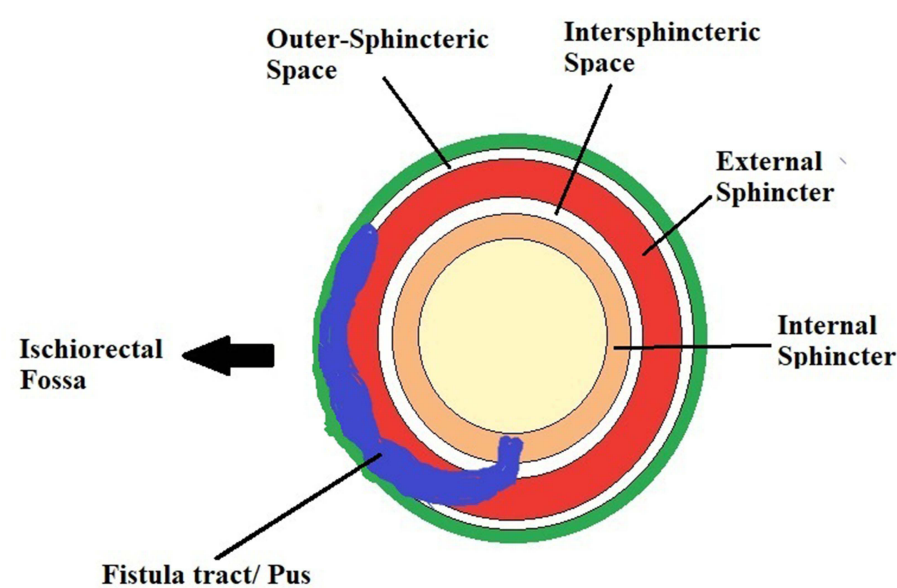

AXIAL SECTION

Figure 9 Schematic diagram highlighting that abscess/fistula tract in the outer-sphincteric space and its propensity to spread to the ischiorectal fossa.

visualized clearly (Figures 2-7). On the other hand, the abscess is seen prominently (hyperintense) on axial section STIR (Short T-1 Inversion Recovery) sequence, but the sphincter muscles are not seen clearly (Figures 2-7).

These preliminary data and the observations based on it strongly suggest the existence of an additional space in the anal sphincter complex (between the external sphincter and its outer fascia). This unrecognized space, the "outersphincteric" space, perhaps acts as an important pathway for pus/fistula spread from the internal sphincter to the ischiorectal fossa and transformation of an intersphincteric fistula to a transsphincteric fistula.

The fistulas usually originate from anal glands, most of which are located in the intersphincteric space at the level of the dentate line. ${ }^{5}$ From the point of origin, one possibility is that the fistula can ascend cephalad between the sphincters in the intersphincteric space and can enter the supralevator space (Figure 8). The second possibility is that the fistula crosses the external anal sphincter (EAS). After crossing the EAS, the pus can either remain confined between the external fascia of EAS and the EAS muscle (outersphincteric space) (Figure 9) or can rupture through the external fascia of EAS to enter the ischioanal space to become a transsphincteric fistula. Technically, the fistula in outersphincteric space is also a transsphincteric fistula, but it does not enter the ischioanal or ischiorectal fossa. The fistula in the outersphincteric space can also spread superiorly along the infero-lateral border of puborectalis and levator-ani muscle to reach the roof of the ischiorectal fossa. As a result, anal fistulas do not arise from the outer-sphincteric space but can spread in this space (Figures 2,6,7 and 9).
At present, the radiologists are reporting the fistulas in the outer-sphincteric space as intersphincteric fistulas as these fistulas do not enter the ischiorectal fossa. Once more studies validate this new space (outer-sphincteric space); then, it would become a standard practice to report fistulas in this space in MRI reports.

\section{Conclusion}

Conventionally in the anal sphincter complex, only one space through which a fistula/pus can spread is considered clinically relevant. This is the intersphincteric space, present between the internal and the external anal sphincter. Radiologically, all tracts in the sphincter complex (between the ischiorectal fossa and the rectal lumen) are considered intersphincteric fistulas. However, it seems that there is a distinct unrecognized anatomical space between the external sphincter and its outer fascia (outersphincteric space). This previously undescribed pathway is distinct from the intersphincteric space; it perhaps plays a pivotal role in the spread of fistula/pus and may have important implications in the management of anal fistulas.

\section{Acknowledgment}

The abstract was presented on 26th April, 2021 in the annual meeting of the American Society of Colon Rectum Surgeons (ASCRS) held at San Diego, CA, USA.

\section{Author Contributions}

All authors contributed to data analysis, drafting or revising the article, have agreed on the journal to which the 
article will be submitted, gave final approval for the version to be published, and agree to be accountable for all aspects of the work.

\section{Disclosure}

The authors report no conflicts of interest in this work.

\section{References}

1. Garg P. Comparison of preoperative and postoperative MRI after fistula-in-ano surgery: lessons learnt from an audit of $1323 \mathrm{MRI}$ at a single centre. World J Surg. 2019;43(6):1612-1622. doi:10.1007/ s00268-019-04926-y

2. Balci S, Onur MR, Karaosmanoglu AD, et al. MRI evaluation of anal and perianal diseases. Diagn Interv Radiol. 2019;25(1):21-27. doi:10.5152/dir.2018.17499

3. Erden A. MRI of anal canal: normal anatomy, imaging protocol, and perianal fistulas: part 1. Abdom Radiol (NY). 2018;43(6):1334-1352. doi:10.1007/s00261-017-1305-2

4. Halligan S, Tolan D, Amitai MM, et al. ESGAR consensus statement on the imaging of fistula-in-ano and other causes of anal sepsis. Eur Radiol. 2020;30(9):4734-4740. doi:10.1007/s00330-020-06826-5
5. Zhang H, Zhou ZY, Hu B, et al. Clinical significance of 2 deep posterior perianal spaces to complex cryptoglandular fistulas. Dis Colon Rectum. 2016;59(8):766-774. doi:10.1097/DCR.000000000 0000628

6. Li YB, Chen JH, Wang MD, et al. Transanal opening of intersphincteric space for fistula-in-ano. Am Surg. 2021;3134821989048. doi: $10.1177 / 0003134821989048$

7. Huang B, Wang X, Zhou D, et al. Treating highly complex anal fistula with a new method of combined intraoperative endoanal ultrasonography (IOEAUS) and transanal opening of intersphincteric space (TROPIS). Videosurg Other Miniinvasive Tech. 2021;16(1). doi:10.5114/wiitm.2021.104368

8. Garg P, Kaur B, Menon GR. Transanal opening of the intersphincteric space: a novel sphincter-sparing procedure to treat 325 high complex anal fistulas with long-term follow-up. Colorectal Dis. 2021;23 (5):1213-1224. doi:10.1111/codi.15555

9. Garg P, Kaur B, Goyal A, Yagnik VD, Dawka S, Menon GR. Lessons learned from an audit of 1250 anal fistula patients operated at a single center: a retrospective review. World J Gastrointest Surg. 2021;13 (4):340-354. doi:10.4240/wjgs.v13.i4.340

10. Parks AG, Gordon PH, Hardcastle JD. A classification of fistula-inano. Br J Surg. 1976;63(1):1-12. doi:10.1002/bjs.1800630102

11. Garg P. Understanding and treating supralevator fistula-in-ano: MRI analysis of 51 cases and a review of literature. Dis Colon Rectum. 2018;61(5):612-621. doi:10.1097/DCR.0000000000 001051
Clinical and Experimental Gastroenterology

\section{Publish your work in this journal}

Clinical and Experimental Gastroenterology is an international, peerreviewed, open access, online journal publishing original research, reports, editorials, reviews and commentaries on all aspects of gastroenterology in the clinic and laboratory. This journal is indexed on American Chemical Society's Chemical Abstracts Service (CAS).

\section{Dovepress}

The manuscript management system is completely online and includes a very quick and fair peer-review system, which is all easy to use. Visit http://www.dovepress.com/testimonials.php to read real quotes from published authors. 